\title{
Early response of right-ventricular function to percutaneous mitral valve repair
}

\author{
Atsushi Sugiura ${ }^{1}$ (1) Jasmin Shamekhi ${ }^{1} \cdot$ Tadahiro Goto $^{2} \cdot$ Maximilian Spieker $^{3} \cdot$ Christos Iliadis $^{4} \cdot$ Refik Kavsur $^{1}$. \\ Victor Mauri ${ }^{4} \cdot$ Malte Kelm $^{3} \cdot$ Stephan Baldus ${ }^{4} \cdot$ Tetsu Tanaka $^{1} \cdot$ Noriaki Tabata $^{5}$. Jan-Malte Sinning ${ }^{6} \cdot$ Marcel Weber $^{1}$.

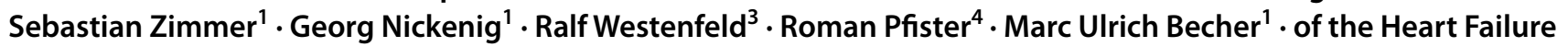 \\ Network Rhineland
}

Received: 10 June 2021 / Accepted: 16 August 2021 / Published online: 20 October 2021

(c) The Author(s) 2021

\begin{abstract}
Background The change in right-ventricular function (RVF) after transcatheter mitral valve repair is still poorly understood. We assessed the early response of RVF to the MitraClip procedure and its clinical relevance.

Methods We analyzed consecutive patients who underwent a MitraClip procedure to treat MR between August 2010 and March 2019 in the Heart Failure Network Rhineland registry. RVF was assessed before and after the procedure. Impaired RVF was defined as an RV fractional area change (RVFAC) $<35 \%$ or tricuspid annular plane systolic excursion (TAPSE) $<16 \mathrm{~mm}$. Results 816 eligible patients ( $77 \pm 9$ years, $58.5 \%$ male) were included in the analysis. Baseline values of RVF were: RVFAC 38.6 (IQR 29.7-46.7) \% and TAPSE 17.0 (IQR 14.0-21.0) $\mathrm{mm}$. At a median time of 3 (IQR 2-5) days after the procedure, the RVF remained normal in 34\% ( $n=274)$, normalized in 17\% $(n=140)$, deteriorated in $15 \%(n=125)$, and was persistently impaired in $34 \%(n=277)$ of patients. The RVF response was significantly associated with a composite outcome of all-cause mortality and hospitalization due to heart failure within a 2-year follow-up. Compared to stable/normal RVF, the adjusted hazard ratios for the outcome were 1.78 (95\% CI 1.10-2.86) for normalized RVF, 1.89 (95\% CI 1.34-3.15) for deteriorated RVF, and 2.25 (95\% CI 1.47-3.44) for persistently impaired RVF. Changes in TAPSE and RVFAC as continuous variables were significantly correlated with the outcome.

Conclusion An early change in RVF following transcatheter mitral valve repair is predictive of mortality and hospitalization due to heart failure during follow-up.
\end{abstract}

Atsushi Sugiura and Jasmin Shamekhi contributed equally to this work.

Atsushi Sugiura

Atsushi.sugiura@ukbonn.de

1 Department of Medicine II, Heart Center Bonn, University Hospital Bonn, Venusberg-Campus 1, 53127 Bonn, Germany

2 Department of Clinical Epidemiology and Health Economics, School of Public Health, University of Tokyo, Tokyo, Japan

3 Department of Cardiology, Heart Center, University Hospital Düsseldorf, Düsseldorf, Germany

4 Department of Cardiology, Heart Center, University Hospital Cologne, Cologne, Germany

5 Department of Cardiovascular Medicine, Graduate School of Medical Sciences, Kumamoto University, Kumamoto, Japan

6 Department of Cardiology, St. Vinzenz-Hospital Cologne, Cologne, Germany 


\section{Graphic abstract}

Early response of RVF after MitraClip and its clinical significance. An acute, early change in RVF can be observed following the MitraClip procedure, which is associated with the risk of mortality and hospitalization for HF.

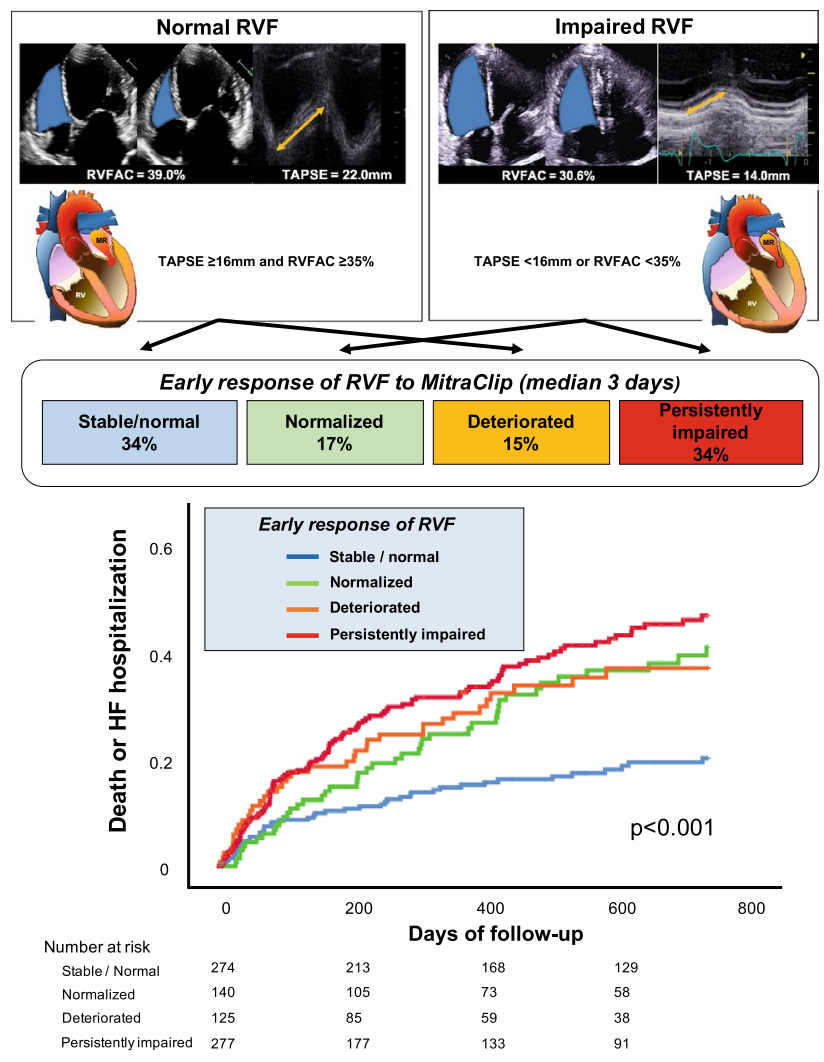

Keywords Transcatheter mitral valve repair $\cdot$ MitraClip $\cdot$ Right ventricular function $\cdot$ Echocardiography $\cdot$ Heart failure Prognosis

\section{Introduction}

Mitral regurgitation (MR) is the most common valvular heart disease [1], which induces pulmonary hypertension and increases RV afterload [2]. Right-ventricular function $(\mathrm{RVF})$ is a pivotal prognostic marker in patients with MR: impaired RVF has been associated with dismal clinical prognosis, as well as an increased risk of mortality and hospitalization due to heart failure (HF) [3].

Treating MR may promote RV unloading and eventually recovery of function, with a potential prognostic benefit. Transcatheter edge-to-edge mitral valve repair using the MitraClip system is a less invasive therapeutic option for patients with MR who are at a high risk of surgical complications [4]. Because RVF is sensitive to both the volume and pressure load, this procedure may offer an acute benefit for RVF. In contrast, an acute deterioration of RVF has also been reported following the MitraClip and is linked to worse clinical outcomes. Nevertheless, data on the early RV response following MitraClip is still lacking. Accordingly, we aimed to investigate the RV response after MitraClip and its impact on clinical outcomes.

\section{Methods}

\section{Study design and setting}

We conducted a retrospective analysis of data from the Heart Failure Network Rhineland registry-a multicenter, prospective, consecutive database that includes information for patients treated at university hospitals in Bonn, Cologne, and Duesseldorf [5]. We reviewed data for patients who underwent MitraClip (Abbott Vascular Inc., Menlo Park, CA) for the treatment of MR between August 2010 and March 2019. All patients had symptomatic MR and were considered ineligible for surgery or at a high risk of surgical 
complications. After a standard diagnostic work-up, which included transesophageal echocardiography and left-heart catheterization, patients were evaluated for the treatment of MR by an interdisciplinary heart team at the individual centers. In accordance with standard institutional protocols, echocardiographic evaluations were performed at baseline and after the procedure. Patients without baseline and postprocedural echocardiographic data were excluded from the analysis.

This study was approved by the ethics committees of the individual centers and was conducted in accordance with the Declaration of Helsinki. All patients provided written informed consent to participate in the registry.

\section{Echocardiographic analysis}

Echocardiographic assessments were performed in accordance with current guidelines [6, 7]. All measurements were reviewed by two independent cardiologists, who were dedicated to echocardiographic evaluation and blinded to the present study. We assessed the severity of MR as follows: grade 0 : none, $1+$ : mild, $2+$ : moderate, $3+$ : moderate-tosevere, and $4+:$ severe. RV dysfunction was defined as the $\mathrm{RV}$ fractional area change (RVFAC) $<35 \%$, which was calculated as [RV end-diastolic area - RV end-systolic area]/ $\mathrm{RV}$ end-diastolic area $\times 100$, or tricuspid annular plane systolic excursion (TAPSE) $<16 \mathrm{~mm}$ [8]. We examined each parameter of RVF before and after the MitraClip procedure. Patients were divided into four groups according to their acute change in RVF: stable/normal, normalized, deteriorated, or persistently impaired RVF.

\section{Clinical endpoints}

The primary outcome was a composite of all-cause mortality and hospitalization due to HF within 2 years. Outcomes were prospectively assessed during scheduled hospital visits or via telephone interviews with the patients' general practitioners and families.

\section{Statistical analysis}

Categorical variables are reported as percentages and were compared using Fisher's exact tests. Continuous variables are reported as the mean \pm standard deviation (SD) or as medians and interquartile ranges (IQRs), as appropriate. Analyses of variance (ANOVAs) were used to compare continuous variables across groups. Changes in RVF before and after MitraClip (within a few days) were assessed using paired $t$ tests or Wilcoxon signed-rank tests.

The Kaplan-Meier method was used to generate eventfree survival curves according to an acute response of RVF. The unadjusted and adjusted Cox proportional hazard models were conducted to estimate the association of the RVF response with outcomes [4, 9]. The models were adjusted for age, sex, coronary artery disease, estimated glomerular filtration rate, New York Heart Association functional class, MR etiology, LV ejection fraction, and TR [4, 9]. We also examined each outcome separately (i.e. mortality, HF hospitalization).

To examine the robustness of our inference, we performed several sensitivity analyses. Cox proportional hazard models were conducted to determine the clinical relevance of the changes in TAPSE (model 1) and in RVFAC (model 2). The models were adjusted for the aforementioned variables and baseline RVF. In addition, we performed a landmarkanalysis during two periods, from discharge to 3 months and from 3 months to 2 years. Finally, associations between the response of RVF and clinical outcomes were assessed separately, according to MR etiology or residual MR.

Two-tailed $p$ values $<0.05$ were considered statistically significant. All statistical analyses were performed using EZR version 1.37 (Saitama Medical Center, Jichi Medical University, Saitama, Japan) and SPSS Statistics version 25.0 (IBM, Armonk, New York).

\section{Results}

\section{Study population}

Baseline and postprocedural RVF data were available for 816 patients during the study period (Fig. 1). Participants were of advanced age (mean $77 \pm 9$ years) and predominantly male (58\%). The median LV ejection fraction was 44.0 (IQR $31.1-57.6$ ) \%, and $60 \%$ of patients had secondary MR. The median RVFAC was 38.6 (IQR 29.7-46.7) \%, the median TAPSE was 17.0 (IQR 14.0-21.0) mm, and impaired RVF was observed in 417 (51\%) patients at baseline. Intraand inter-class correlations of the RVFAC measurement were 0.907 and 0.831 for baseline and 0.899 and 0.766 for after the procedure. A successful implantation of clips was achieved in $98 \%$ of patients.

\section{Early response of RVF to MitraClip}

Post-procedural echocardiography was performed at a median time of 3 (IQR 2-5) days after the procedure. Overall, RVFAC increased significantly (from 38.3 to $40.1 \%$, $p<0.001$ ), while there was no significant change in TAPSE (from 17.9 to $18.1 \mathrm{~mm}, p=0.21$ ). Patients were divided into groups according to their change in RVF. Among the study population, after the procedure, 274 (34\%) patients showed stable/normal RVF, 140 (17\%) patients showed normalization of RVF, 125 patients (15\%) exhibited deterioration 
Fig. 1 Study population. Baseline and post-procedural RVF data were available for 816 patients. Of these, 399 (49\%) patients presented with normal RVF at baseline. Post-procedural echocardiography was performed after a median time of 3 days

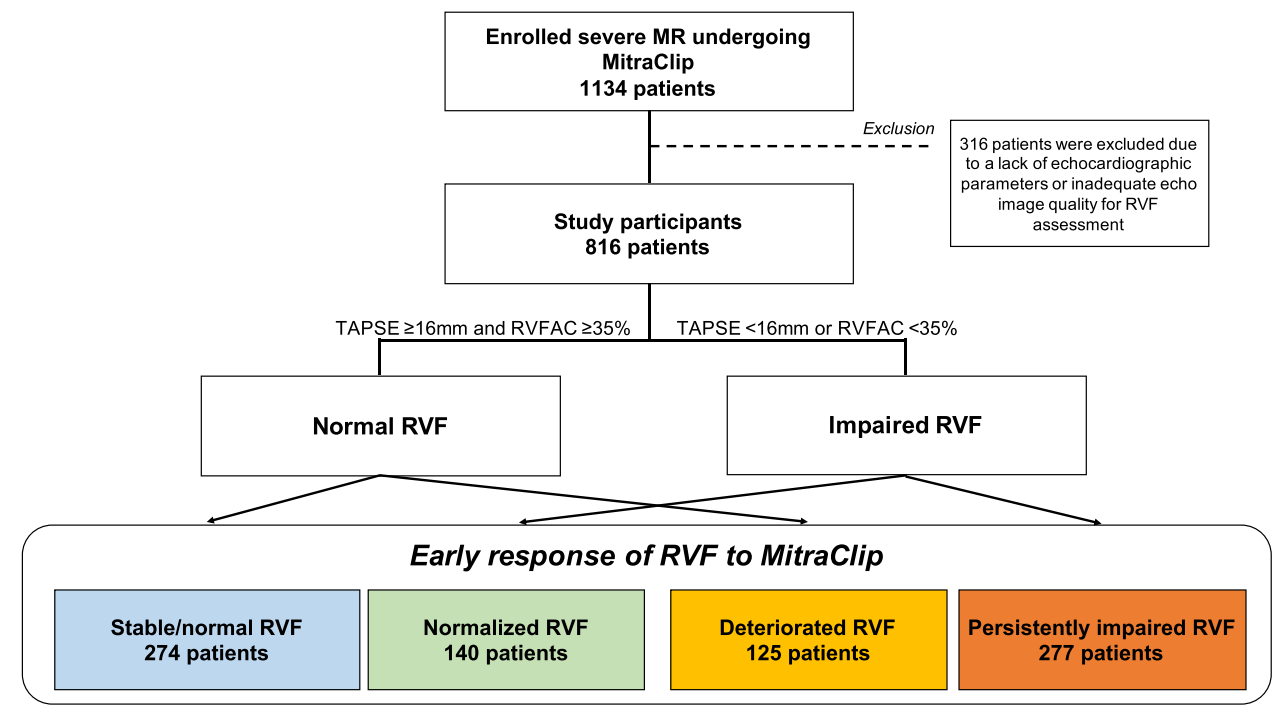

of RVF, while 277 (34\%) patients exhibited persistently impaired RVF (Fig. 1).

The baseline characteristics of each group are summarized in Table 1. Compared to patients with stable/normal RVF, patients with normalized, acutely impaired, or persistently impaired RVF presented with more advanced cardiovascular disease at baseline as evidenced by having higher levels of N-terminal pro-B-type natriuretic peptide, lower $\mathrm{LV}$ ejection fraction, larger LV volume, larger RV area, and more severe tricuspid regurgitation (TR).

The echocardiographic parameters following MitraClip are summarized in Supplemental Table 1. A reduction in MR was consistently observed among the groups $(p=0.50)$. As compared to patients with stable/normal or normalized RVF, patients with deteriorated RVF or persistently impaired RVF showed slightly higher pulmonary arterial pressure $(p=0.02)$ and more severe TR $(p<0.001)$ after the procedure. Changes in the main echocardiographic variables are depicted in Fig. 2. We did find a correlation between the change in RVFAC and the change in TAPSE $(r=0.14$, $p<0.001)$. However, there was no significant difference with regard to a reduction in systolic pulmonary arterial pressure among the groups, and the LV ejection fraction tended to decrease in patients with deteriorated RVF.

\section{Clinical consequences of the early RVF response}

After a median follow-up of 542 days (IQR 246-897 days), 149 patients had died and 114 patients had been hospitalized due to HF. This means that in total 230 patients $(28.2 \%)$ experienced the predefined primary endpoint within 2 years after MitraClip. The incidence of the primary outcome differed significantly according to the RVF response (Fig. 3a). Patients with stable/normal RVF had a significantly lower incidence of the primary outcome than patients with acutely deteriorated RVF $(20.0 \%$ vs. $36.3 \%, p=0.001)$. In addition, patients with normalized RVF had a numerically lower incidence of the primary endpoint than patients with persistently impaired RVF ( $40.1 \%$ vs. $46.0 \%, p=0.13$ ), although the difference did not reach statistical significance at the 2-year follow-up. Similarly, the incidence of all-cause mortality (log-rank $p=0.006$ : Fig. $3 b$ ) or HF hospitalization differed significantly (log-rank $p<0.001$ : Fig. $3 \mathrm{c}$ ) across the groups.

The RVF response was found to be predictive of the occurrence of the primary outcome. The hazard ratios for the composite endpoint vs. stable/normal RVF were 2.05 (1.35-3.10) for normalized RVF, 2.14 (1.38-3.31) for deteriorated RVF, and 2.66 (1.87-3.77) for persistently impaired $\mathrm{RVF}$, all with a $p$ value $<0.001$ (Table 2). The association of adjusted variables to the composite outcome are presented in Supplemental Table 2. The RVF response was independently associated with the primary endpoint after adjustment for the predefined covariates (Table 2).

Multivariable models were calculated using the change in TAPSE and that in RVFAC, as shown in Table 3. While a lower TAPSE at baseline was predictive for a worse prognosis, the change in TAPSE was negatively associated with the outcome. Similarly, a decreased RVFAC at baseline was a predictive factor for the outcome, while an increase in RVFAC after MitraClip was associated with a lower risk of the primary composite outcome.

\section{Landmark analysis}

We also evaluated the primary outcome during two distinct time periods, from discharge to 3 months and from 3 months to 2 years (Fig. 3d). Up to 3 months, patients with normalized RVF had a better outcome than those with persistently impaired RVF. In contrast, beyond 3 months, there were no significant differences in the 
Table 1 Baseline characteristics according to response of right ventricular function

\begin{tabular}{|c|c|c|c|c|c|c|}
\hline & Overall $(n=816)$ & $\begin{array}{l}\text { Stable/normal } \\
(n=274)\end{array}$ & $\begin{array}{l}\text { Normalized } \\
(n=140)\end{array}$ & $\begin{array}{l}\text { Deteriorated } \\
(n=125)\end{array}$ & $\begin{array}{l}\text { Persistently impaired } \\
(n=277)\end{array}$ & $p$ value \\
\hline Age, years & $77 \pm 9$ & $78 \pm 8$ & $76 \pm 10$ & $78 \pm 8$ & $76 \pm 9$ & 0.03 \\
\hline Sex male & $477(58.5)$ & 134 (48.9) & $76(54.3)$ & $69(55.2)$ & 198 (72.6) & $<0.001$ \\
\hline $\begin{array}{l}\text { Body surface area, } \\
\mathrm{m}^{2}\end{array}$ & $1.87 \pm 0.22$ & $1.86 \pm 0.22$ & $1.86 \pm 0.22$ & $1.85 \pm 0.21$ & $1.90 \pm 0.21$ & 0.09 \\
\hline Hypertension & $637(78.1)$ & $213(77.7)$ & $111(79.3)$ & $93(74.4)$ & $220(79.4)$ & 0.70 \\
\hline Diabetes & $242(29.7)$ & $68(24.8)$ & 43 (30.7) & $33(26.4)$ & $98(35.4)$ & 0.04 \\
\hline Atrial fibrillation & $545(66.8)$ & $172(62.8)$ & $90(65.2)$ & $90(72.0)$ & 193 (69.7) & 0.20 \\
\hline $\begin{array}{l}\text { Coronary artery } \\
\text { disease }\end{array}$ & $507(62.1)$ & $151(55.3)$ & $91(65.0)$ & $78(62.4)$ & $187(67.5)$ & 0.03 \\
\hline COPD & $157(19.2)$ & 60 (21.9) & $24(17.1)$ & $29(23.4)$ & $44(15.9)$ & 0.17 \\
\hline $\begin{array}{l}\text { Prior cardiac device } \\
\text { implantation }^{\mathrm{a}}\end{array}$ & 317 (38.9) & $78(28.5)$ & $49(35.0)$ & $56(44.8)$ & $134(48.4)$ & $<0.001$ \\
\hline EuroSCORE, \% & $18.3(10.0-30.4)$ & $16.0(9.0-27.6)$ & $18.4(10.6-30.1)$ & $19.0(10.8-29.7)$ & $20.0(10.5-33.4)$ & 0.02 \\
\hline $\begin{array}{l}\text { NYHA class IV, } n \\
(\%)\end{array}$ & $141(17.3)$ & $47(19.1)$ & $22(18.0)$ & $21(20.2)$ & $51(23.2)$ & 0.64 \\
\hline NT-pro-BNP, pg/ml & 2884 (1481-6119) & $2026(927-3682)$ & $2706(1453-5044)$ & $2645(1614-5767)$ & $4523(2162-11,913)$ & $<0.001$ \\
\hline $\begin{array}{l}\text { Estimated GFR, mL/ } \\
\min / 1.73 \mathrm{~m}^{2}\end{array}$ & $46.0(33.0-61.0)$ & $48.2(35.9-62.5)$ & $45.8(35.0-59.0)$ & $49.5(32.0-62.5)$ & $43.5(30.4-59.0)$ & 0.11 \\
\hline $\begin{array}{l}\text { LV ejection fraction, } \\
\%\end{array}$ & $44.0(31.1-57.6)$ & $53.0(39.8-60.0)$ & $43.8(31.7-58.0)$ & $46.3(33.5-59.1)$ & $34.9(26.7-50.0)$ & $<0.001$ \\
\hline $\begin{array}{l}\mathrm{LV} \text { end-diastolic vol- } \\
\text { ume index, } \mathrm{ml} / \mathrm{m}^{2}\end{array}$ & $69.8(53.2-93.3)$ & $64.0(51.9-81.0)$ & $66.9(50.0-92.7)$ & $68.2(52.6-92.0)$ & $81.5(59.5-104.8)$ & $<0.001$ \\
\hline $\begin{array}{l}\text { LV end-systolic vol- } \\
\text { ume index, } \mathrm{ml} / \mathrm{m}^{2}\end{array}$ & $36.1(22.9-61.1)$ & $29.3(20.2-46.5)$ & $33.0(20.7-58.99$ & $33.8(22.9-60.1)$ & $51.5(29.4-71.2)$ & $<0.001$ \\
\hline $\begin{array}{l}\text { Left atrial volume } \\
\text { index, } \mathrm{ml} / \mathrm{m}^{2}\end{array}$ & $51.8(41.1-68.6)$ & $46.8(36.6-63.3)$ & $52.6(42.0-73.5)$ & $54.0(44.7-69.9)$ & $54.6(44.1-69.0)$ & 0.002 \\
\hline $\mathrm{MR} \geq 3+$ & $687(84.2)$ & $235(85.8)$ & 117 (83.6) & $96(76.8)$ & $239(86.3)$ & 0.09 \\
\hline EROA, $\mathrm{cm}^{2}$ & $0.29(0.20-0.38)$ & $0.28(0.20-0.36)$ & $0.35(0.20-0.35)$ & $0.26(0.20-0.35)$ & $0.30(0.21-0.40)$ & 0.06 \\
\hline Secondary MR & $487(60.0)$ & $151(55.1)$ & $73(52.1)$ & $81(64.8)$ & $182(65.7)$ & 0.01 \\
\hline RVFAC, $\%$ & $38.6(29.7-46.7)$ & $45.5(40.0-50.9)$ & $31.7(27.3-37.8)$ & $44.3(39.0-51.2)$ & $29.5(23.8-34.4)$ & $<0.001$ \\
\hline TAPSE, mm & $17.0(14.0-21.0)$ & $19.0(17.0-22.0)$ & $15.0(13.0-19.0)$ & $19.0(15.0-19.0)$ & $14.0(12.0-16.0)$ & $<0.001$ \\
\hline $\begin{array}{l}\mathrm{RV} \text { end-diastolic area } \\
\text { index, } \mathrm{cm}^{2} / \mathrm{m}^{2}\end{array}$ & $10.6(8.9-13.1)$ & $9.4(7.5-11.0)$ & $10.6(8.9-12.8)$ & $10.8(9.3-12.9)$ & $12.1(10.0-15.1)$ & $<0.001$ \\
\hline $\begin{array}{l}\text { Right atrial area } \\
\text { index, } \mathrm{cm}^{2} / \mathrm{m}^{2}\end{array}$ & $12.7(10.0-16.0)$ & $11.1(9.0-14.1)$ & $12.1(10.2-16.5)$ & $13.3(10.9-16.2)$ & $14.1(11.6-17.5)$ & $<0.001$ \\
\hline $\mathrm{TR} \geq 3+$ & $168(20.6)$ & $34(12.4)$ & $25(17.9)$ & $34(27.2)$ & $75(27.2)$ & $<0.001$ \\
\hline SPAP, mmHg & $46.3(37.0-58.0)$ & $45.0(35.1-55.0)$ & $48.0(38.0-59.5)$ & $45.2(39.0-57.8)$ & $49.0(37.0-60.0)$ & 0.23 \\
\hline
\end{tabular}

Values are mean $\pm \mathrm{SD}, \mathrm{n}(\%)$, or median (25th percentile, 75 th percentile)

$C O P D$ chronic obstructive pulmonary disease, $E R O A$ effective regurgitant orifice area, GFR glomerular filtration rate, $I Q R$ interquartile range, $L V$ left ventricular, $M R$ mitral regurgitation, $N Y H A$ New York Heart Association, $R V$ right-ventricular, $R V F A C$ right ventricular fractional area change, SPAP systolic pulmonary arterial pressure, TAPSE tricuspid annular plane systolic excursion, TR tricuspid regurgitation

${ }^{a}$ Pacemaker/intracardiac defibrillator/cardiac resynchronization therapy

outcome between the normalized, deteriorated, and persistently impaired RVF patients, all of which showed a significantly higher incidence of the primary endpoint compared to patients with stable/normal RVF.

\section{Subgroup analyses}

We analyzed two different subgroups, stratified by MR etiology and LV ejection fraction (Supplemental Fig. 1). The 


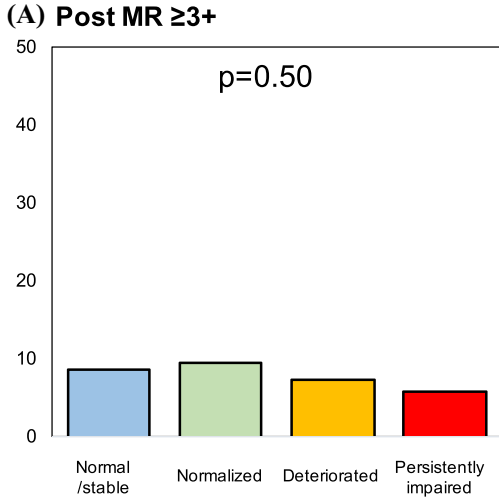

(B) Change in SPAP

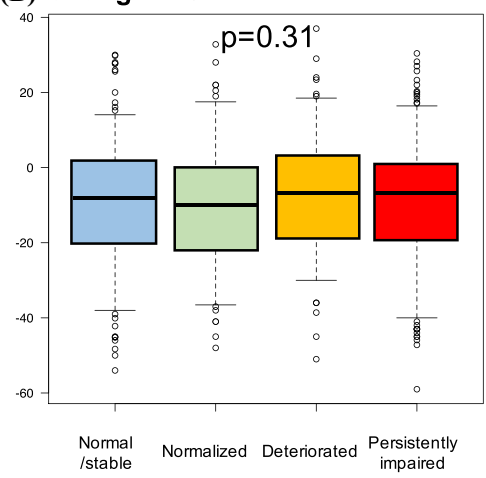

(C) Change in TAPSE

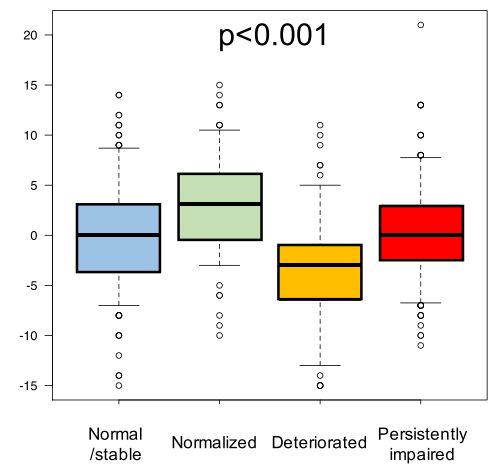

(D) Change in RVFAC

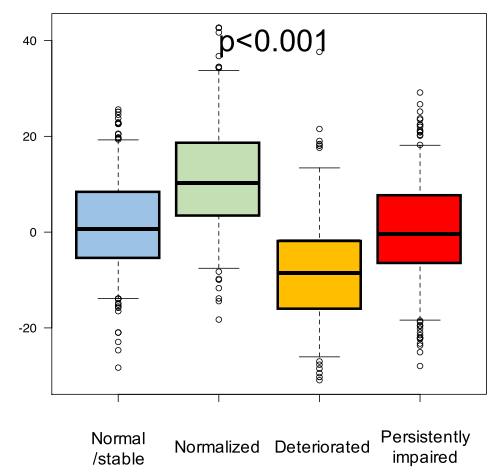

(E) Change in LVEF

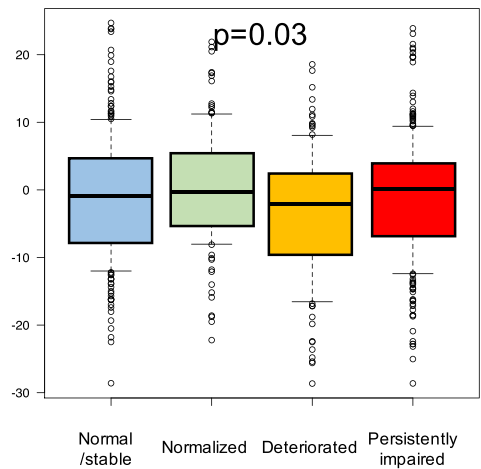

(F)

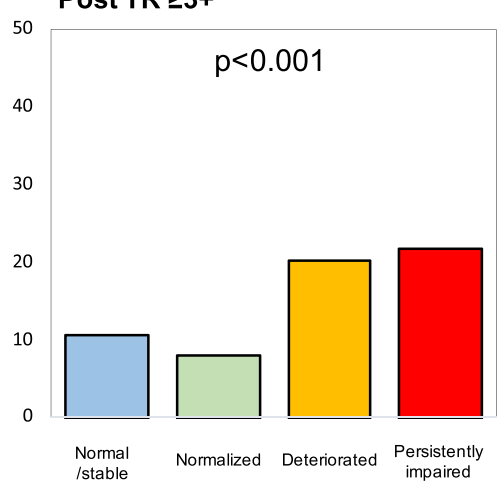

Fig. 2 Changes in echocardiographic parameters. A reduction in a MR and b SPAP was consistently observed among the groups. Changes in $\mathbf{c}$ TAPSE and d RVFAC were correlated. e Patients with

association of the RVF response with the primary composite outcome of mortality and HF hospitalization were consistent across the subgroups by MR etiology or by LV ejection fraction. Cox proportional models are shown in Supplemental Table 3. With the limited sample size, the associations of each RVF response with the primary outcome were consistent across the subgroups.

\section{Discussion}

This is the first study assessing the response of RVF in the acute phase following the MitraClip procedure and its clinical implications for patients with MR. The main findings can be summarized as follows:

1. A change or response in RVF can be observed within a median of 3 days following MitraClip.

2. RVF remained normal in $34 \%$, normalized in $17 \%$, and deteriorated in $15 \%$ of patients, while $34 \%$ of patients had persistently impaired RVF.

3. The early response in RVF was associated with the primary composite outcome of all-cause mortality and deteriorated RVF showed a substantial reduction of the LV ejection fraction. $\mathbf{f}$ Patients with deteriorated or persistently impaired RVF had a higher incidence of TR classified as severe or worse

hospitalization due to HF: excess risk persisted after the adjustment (adjusted hazard ratio 1.78 [1.10-2.86] for normalized RVF, 1.89 [1.34-3.15] for deteriorated RVF, and 2.25 [1.47-3.44] for persistently impaired RVF, compared to stable/normal RVF) (Graphical abstract).

\section{Early response of RVF following MitraClip}

Impairment of RVF often coincides with MR because of pulmonary hypertension and increased RV afterload. Decreases in MR can reduce the volume overload of the LA and LV, thereby decreasing RV afterload [10]. Previous cohort studies have reported improvements in RVF 6 months and 1 year after the MitraClip procedure [11-13]. However, given that the RV is sensitive to volume and pressure load, treatment for MR can exert acute effects on RVF in the early postoperative period.

We found that $17 \%$ of patients showed a normalization of RVF after MitraClip. Conversely, $15 \%$ of the study population showed an acute deterioration of RVF. Such early variation of RVF is novel but consistent with a prior study showing that $20 \%$ of patients undergoing MitraClip showed worsening RVF over a median of 4.9-months follow-up [13]. 
(A) Composite of death and HF hospitalization

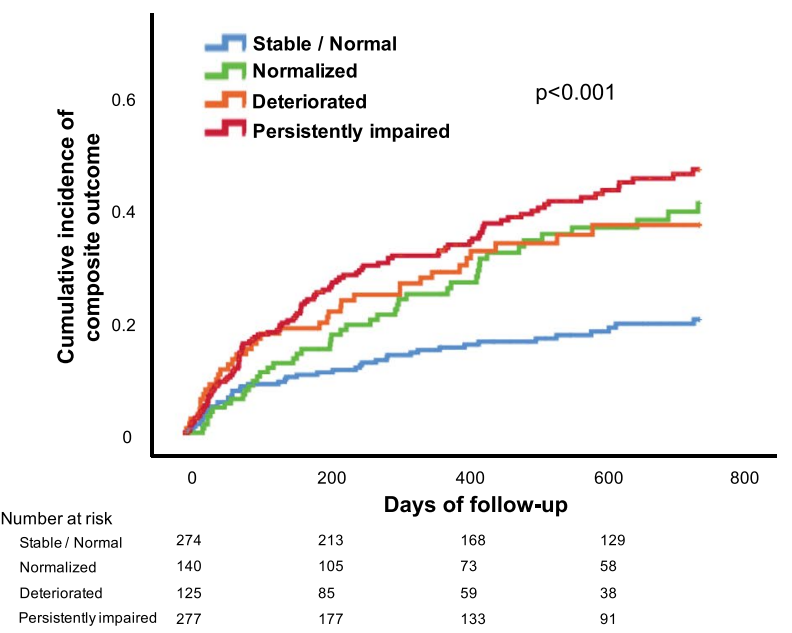

(C) HF hospitalization

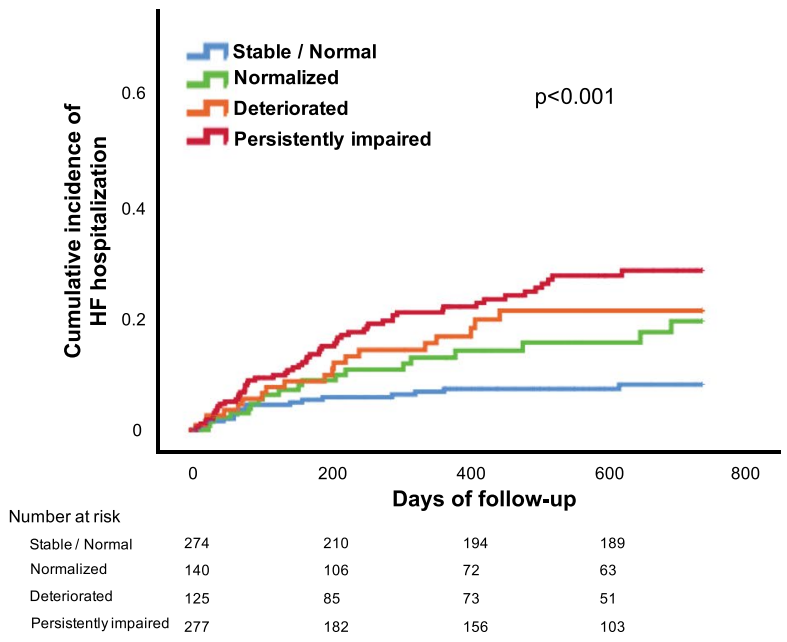

Fig. 3 Cumulative incidence of outcomes according to RVF response. Kaplan-Meier curves up to 2-year follow-up for a composite outcome of all-cause mortality and HF hospitalization, b all-cause mortality,

Such deterioration could be a consequence of an iatrogenic atrial septal defect (iASD) [14]. A post-procedural iASD following MitraClip can lead to right-heart failure due to volume overload of the RV and progressive TR [15]. Furthermore, ischemic etiology and reduced LV ejection fraction could be factors associated with increased shunt flow after MitraClip [16]. This relationship can be further underlined by our finding that patients with deteriorated RVF presented with a lower LV ejection fraction and more often had coronary artery disease. Alternatively, the early worsening of RVF could also be attributed to the interplay between LV and RV [13]. In the current study, patients with deteriorated RVF showed a decline in the LV ejection fraction. An increase in LV afterload may occur following a reduction in
(B) All-cause mortality

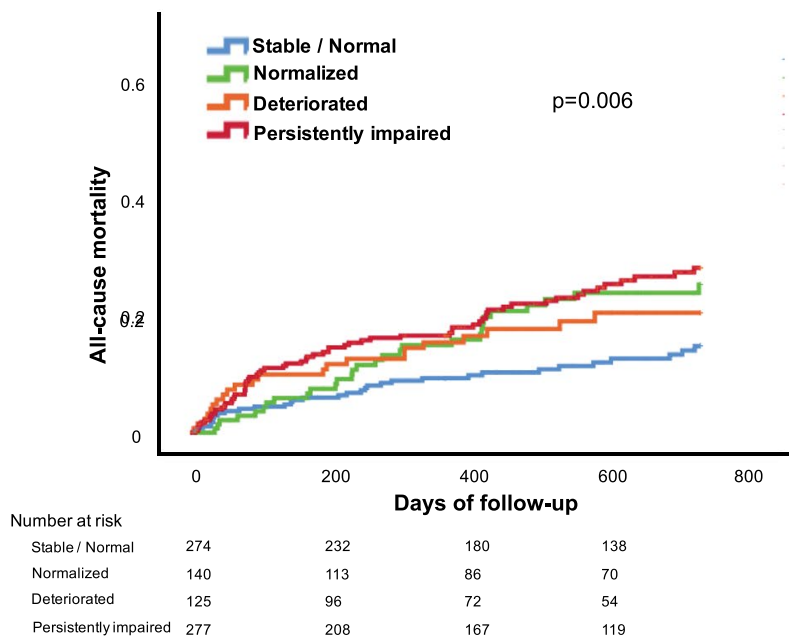

(D) Landmark analysis for composite outcome

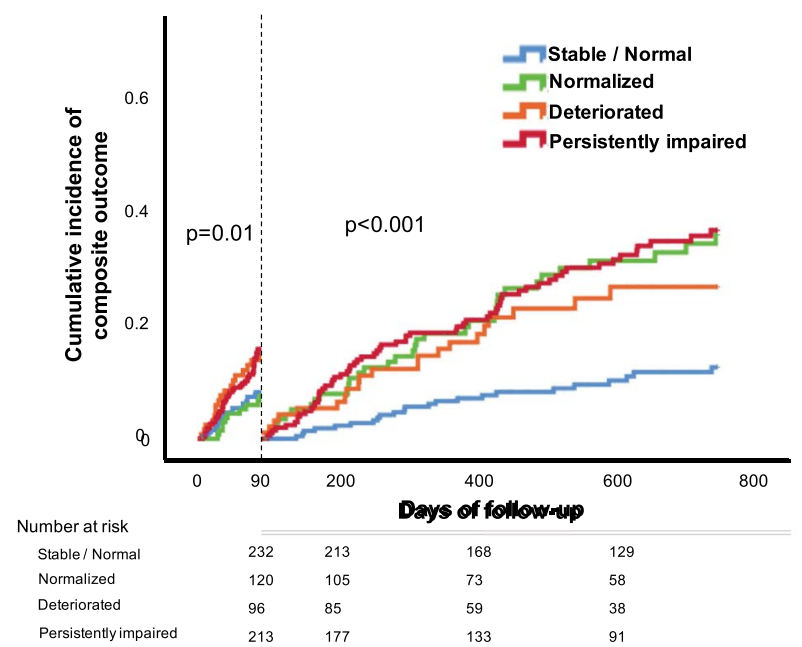

and $\mathbf{c}$ HF hospitalization, according to the early RVF response. d A landmark analysis for the composite outcome during two periods, from discharge to 3 months and from 3 months to 2 years

MR [17], which may, in turn, result in elevated LV filling pressure and thereby exert a negative impact on RVF.

\section{Clinical consequences of RVF response}

Impairment of RVF has been shown to be associated with unfavorable outcomes in the setting of HF. However, conflicting data exist for transcatheter edge-to-edge mitral valve repair [18, 19]. Kaneko et al. reported that baseline impairment of RVF was associated with higher mortality in patients with secondary MR and LVEF < 40\% [19], while Godino et al. and Ledwoch et al. have reported that the RVF at baseline did not affect the outcome $\left[13,18^{]}\right.$. Our results could contribute to a reconciliation of these conflicting data. 
Table 2 Association between response of RVF and clinical outcomes

\begin{tabular}{|c|c|c|c|c|c|c|}
\hline & \multicolumn{3}{|l|}{ Unadjusted } & \multicolumn{3}{|l|}{ Adjusted } \\
\hline & HR & $95 \%$ CI & $p$ value & HR & $95 \%$ CI & $p$ value \\
\hline \multicolumn{7}{|l|}{ Composite outcome } \\
\hline Stable/normal & Reference & & & Reference & & \\
\hline Normalized & 2.05 & $1.35-3.10$ & $<0.001$ & 1.78 & $1.10-2.86$ & 0.02 \\
\hline Deteriorated & 2.14 & $1.38-3.31$ & $<0.001$ & 1.89 & $1.34-3.15$ & 0.01 \\
\hline Persistently impaired & 2.66 & $1.87-3.77$ & $<0.001$ & 2.25 & $1.47-3.44$ & $<0.001$ \\
\hline \multicolumn{7}{|l|}{ All-cause mortality } \\
\hline Stable/normal & Reference & & & Reference & & \\
\hline Normalized & 1.78 & $1.08-2.93$ & 0.02 & 1.74 & $1.00-3.04$ & 0.05 \\
\hline Deteriorated & 1.60 & $0.93-2.75$ & 0.09 & 1.58 & $0.85-2.92$ & 0.15 \\
\hline Persistently impaired & 2.09 & $1.38-3.18$ & $<0.001$ & 2.04 & $1.24-3.38$ & 0.005 \\
\hline \multicolumn{7}{|l|}{ HF hospitalization } \\
\hline Stable/normal & Reference & & & Reference & & \\
\hline Normalized & 2.17 & $1.14-4.14$ & 0.02 & 1.77 & $0.80-3.94$ & 0.16 \\
\hline Deteriorated & 2.68 & $1.41-5.11$ & 0.003 & 2.38 & $1.08-5.28$ & 0.03 \\
\hline Persistently impaired & 3.63 & $2.14-6.17$ & $<0.001$ & 3.06 & $1.57-5.95$ & $<0.001$ \\
\hline
\end{tabular}

$C I$ confidence interval, $H F$ heart failure, $H R$ hazard ratio, $R V F$ right ventricular function

Table 3 Cox proportional regression analysis using change in right ventricular function

\begin{tabular}{|c|c|c|c|c|c|c|}
\hline & \multicolumn{3}{|l|}{ Model 1} & \multicolumn{3}{|l|}{ Model 2} \\
\hline & Adjusted-HR & $95 \% \mathrm{CI}$ & $p$ value & Adjusted-HR & $95 \% \mathrm{CI}$ & $p$ value \\
\hline Change in TAPSE (increase per $1 \mathrm{~mm}$ ) & 0.95 & $0.91-0.98$ & 0.003 & & & \\
\hline Baseline TAPSE $<16 \mathrm{~mm}$ & 1.73 & $1.19-2.52$ & 0.004 & & & \\
\hline Change in RVFAC (increase per 10\%) & & & & 0.83 & $0.71-0.96$ & 0.01 \\
\hline Baseline RVFAC $<35 \%$ & & & & 2.10 & $1.45-3.02$ & $<0.001$ \\
\hline Age (increase per 1 year) & 0.97 & $0.95-0.99$ & 0.007 & 0.99 & $0.97-1.01$ & 0.18 \\
\hline Sex male & 1.31 & $0.89-1.91$ & 0.17 & 1.07 & $0.74-1.53$ & 0.73 \\
\hline Coronary artery disease & 1.57 & $1.06-2.32$ & 0.02 & 1.40 & $0.97-2.03$ & 0.07 \\
\hline Estimated GFR (increase per $1 \mathrm{~mL} / \mathrm{min} / 1.73 \mathrm{~m}^{2}$ ) & 0.98 & $0.98-0.99$ & 0.006 & 0.98 & $0.98-0.99$ & 0.003 \\
\hline NYHA functional class IV & 1.85 & $1.28-2.68$ & 0.001 & 1.98 & $1.40-2.80$ & $<0.001$ \\
\hline Secondary MR & 1.13 & $0.79-1.63$ & 0.50 & 1.13 & $0.80-1.60$ & 0.48 \\
\hline LV ejection fraction $<50 \%$ & 0.84 & $0.56-1.24$ & 0.38 & 0.79 & $0.55-1.13$ & 0.19 \\
\hline $\mathrm{TR} \geq 3+$ & 1.45 & $0.99-2.11$ & 0.06 & 1.36 & $0.95-1.96$ & 0.09 \\
\hline
\end{tabular}

$C I$ confidence interval, GFR glomerular filtration rate, $H R$ hazard ratio, $L V$ left ventricular, $M R$ mitral regurgitation, NYHA New York Heart Association, RVFAC right ventricular fractional area change, TAPSE tricuspid annular plane systolic excursion, TR tricuspid regurgitation

Unloading the RV may promote RV recovery, with a potential prognostic benefit $[13]$. In the current study, acute increases in TAPSE or RVFAC were correlated with a lower risk of the composite outcome at 2 years. Nevertheless, patients with normalized RVF still had a worse outcome compared to patients with stable/normal RVF at 2 years. The worse clinical prognosis of patients with acute normalized RVF after MitraClip might be explained by having more highly impaired kidney function, a higher prevalence of coronary artery disease, and a lower LV ejection fraction. Our findings suggest that baseline comorbidities could attenuate the benefits of RVF improvement over the long-term follow-up.

Rapid worsening of RVF was also found to be detrimental. Acute changes in TAPSE or RVFAC were negatively associated with the risk of outcomes by a Cox regression analysis, independent of baseline RVF. Our findings not only highlight that we should focus on patients who could be at a higher risk for adverse outcomes but also imply that certain adjunctive therapies after transcatheter edge-to-edge mitral valve repair could be beneficial. Closure of the iASD has been linked to reducing the right-heart volume overload [20, 
21]. Yet, the implications of iASD deserve some additional consideration. Lurz et al. have recently reported no prognostic benefit of an iASD closure in patients with persistent iASD 1 month after transcatheter mitral valve repair [22]. Further investigation is still needed to identify the subjects who would benefit from an iASD closure, especially with respect to the acute RVF response. Otherwise, given that patients with deteriorated RVF also had more severe TR, transcatheter treatment of their TR might improve the prognosis in this subgroup [23].

Not surprisingly, persistently impaired RVF was associated with the worst outcome. In this subgroup, the RVF impairment may be the consequence of long-lasting RV afterload. Thus, it could be representative of the 'epiphenomenon' of intrinsic myocardial damage [24]. Therefore, in these cases, RVF could not be improved by reducing MR by using a MitraClip. The timing of MR interventions should be considered carefully when determining the most appropriate treatment for HF.

\section{Limitations}

Several limitations have to be considered when interpreting our findings. The present study was retrospective in nature, which may have introduced a selection bias. Furthermore, although the present cohort of patients undergoing MitraClip with the assessment of RVF is the largest study of its kind so far, the sample size is still limited. Therefore, the correlation of the primary outcome with RVF response may not have been fully adjusted. Nevertheless, the associations we found were significant across several sensitivity analyses.

\section{Conclusions}

Following transcatheter edge-to-edge mitral valve repair, there can be an acute change in RVF, even after a few days. In this study, the early RVF response was associated with the primary composite outcome of all-cause mortality and hospitalization due to HF. Our findings highlight that RVF should be carefully assessed shortly after transcatheter edgeto-edge mitral valve repair, as well as left-side heart function and MR. Strategies to improve post-procedural hemodynamics need to be explored further.

Supplementary Information The online version contains supplementary material available at https://doi.org/10.1007/s00392-021-01951-7.

Acknowledgements We thank Dr. Meghan Lucas (scientific coordinator for the Heart Center Bonn, Bonn, Germany) for proofreading the manuscript.
Funding Open Access funding enabled and organized by Projekt DEAL. This research did not receive any specific grant from funding agencies in the public, commercial, or not-for-profit sectors.

Availability of data and material All the data underlying this article are available in the article and in its online supplementary material.

\section{Declarations}

Conflict of interest G. Nickenig and S. Baldus have received research grants and speaker honoraria from Abbott, outside the submitted work. R. Pfister and C. Iliadis have received travel support by Abbott, outside the submitted work. All other authors report no relationship with industry and other entities.

Ethics approval/consent to participate/consent for publication This study was approved by the ethics committees of the individual centers and was conducted in accordance with the Declaration of Helsinki. All patients provided written informed consent to participate in the registry.

Open Access This article is licensed under a Creative Commons Attribution 4.0 International License, which permits use, sharing, adaptation, distribution and reproduction in any medium or format, as long as you give appropriate credit to the original author(s) and the source, provide a link to the Creative Commons licence, and indicate if changes were made. The images or other third party material in this article are included in the article's Creative Commons licence, unless indicated otherwise in a credit line to the material. If material is not included in the article's Creative Commons licence and your intended use is not permitted by statutory regulation or exceeds the permitted use, you will need to obtain permission directly from the copyright holder. To view a copy of this licence, visit http://creativecommons.org/licenses/by/4.0/.

\section{References}

1. Nkomo VT, Gardin JM, Skelton TN, Gottdiener JS, Scott CG, Enriquez-Sarano M (2006) Burden of valvular heart diseases: a population-based study. Lancet (London, England) 368:1005-1011

2. Voelkel NF, Quaife RA, Leinwand LA, Barst RJ, McGoon MD, Meldrum DR, Dupuis J, Long CS, Rubin LJ, Smart FW, Suzuki YJ, Gladwin M, Denholm EM, Gail DB (2006) Right ventricular function and failure: report of a National Heart, Lung, and Blood Institute working group on cellular and molecular mechanisms of right heart failure. Circulation 114:1883-1891

3. Dini FL, Conti U, Fontanive P, Andreini D, Banti S, Braccini L, De Tommasi SM (2007) Right ventricular dysfunction is a major predictor of outcome in patients with moderate to severe mitral regurgitation and left ventricular dysfunction. Am Heart J 154:172-179

4. Nickenig G, Estevez-Loureiro R, Franzen O, Tamburino C, Vanderheyden M, Luscher TF, Moat N, Price S, Dall'Ara G, Winter R, Corti R, Grasso C, Snow TM, Jeger R, Blankenberg S, Settergren M, Tiroch K, Balzer J, Petronio AS, Buttner HJ, Ettori F, Sievert H, Fiorino MG, Claeys M, Ussia GP, Baumgartner H, Scandura S, Alamgir F, Keshavarzi F, Colombo A, Maisano F, Ebelt H, Aruta P, Lubos E, Plicht B, Schueler R, Pighi M, Di Mario C, Transcatheter Valve Treatment Sentinel Registry Investigators of the ERPotESoC (2014) Percutaneous mitral valve edge-to-edge repair: in-hospital results and 1-year follow-up of 628 patients 
of the 2011-2012 Pilot European Sentinel Registry. J Am Coll Cardiol 64:875-884

5. Iliadis C, Spieker M, Kavsur R, Metze C, Hellmich M, Horn P, Westenfeld R, Tiyerili V, Becher MU, Kelm M, Nickenig G, Baldus S , Pfister R (2021) "Get with the guidelines Heart Failure Risk Score" for mortality prediction in patients undergoing MitraClip. Clin Res Cardiol.https://doi.org/10.1007/ s00392-021-01804-3

6. Falk V, Baumgartner H, Bax JJ, De Bonis M, Hamm C, Holm PJ, Iung B, Lancellotti P, Lansac E, Munoz DR, Rosenhek R, Sjogren J, Tornos Mas P, Vahanian A, Walther T, Wendler O, Windecker S, Zamorano JL, Group ESCSD (2017) 2017 ESC/ EACTS guidelines for the management of valvular heart disease. Eur J Cardiothorac Surg 52:616-664

7. Nishimura RA, Otto CM, Bonow RO, Carabello BA, Erwin JP 3rd, Fleisher LA, Jneid H, Mack MJ, McLeod CJ, O'Gara PT, Rigolin VH, Sundt TM 3rd, Thompson A (2017) 2017 AHA/ ACC focused update of the 2014 AHA/ACC guideline for the management of patients with valvular heart disease: a report of the American College of Cardiology/American Heart Association Task Force on Clinical Practice Guidelines. J Am Coll Cardiol 70:252-289

8. Stolfo D, Tonet E, Merlo M, Barbati G, Gigli M, Pinamonti B, Ramani F, Zecchin M, Sinagra G (2016) Early right ventricular response to cardiac resynchronization therapy: impact on clinical outcomes. Eur J Heart Fail 18:205-213

9. Puls M, Lubos E, Boekstegers P, von Bardeleben RS, Ouarrak T, Butter C, Zuern CS, Bekeredjian R, Sievert H, Nickenig G, Eggebrecht H, Senges J, Schillinger W (2016) One-year outcomes and predictors of mortality after MitraClip therapy in contemporary clinical practice: results from the German transcatheter mitral valve interventions registry. Eur Heart J 37:703-712

10. Siegel RJ, Biner S, Rafique AM, Rinaldi M, Lim S, Fail P, Hermiller J, Smalling R, Whitlow PL, Herrmann HC, Foster E, Feldman T, Glower D, Kar S (2011) The acute hemodynamic effects of MitraClip therapy. J Am Coll Cardiol 57:1658-1665

11. Giannini C, Petronio AS, De Carlo M, Guarracino F, Conte L, Fiorelli F, Pieroni A, Di Bello V (2014) Integrated reverse left and right ventricular remodelling after MitraClip implantation in functional mitral regurgitation: an echocardiographic study. Eur Heart J Cardiovasc Imaging 15:95-103

12. Vitarelli A, Mangieri E, Capotosto L, Tanzilli G, D'Angeli I, Viceconte N, Placanica A, Placanica G, Cocco N, Ashurov R, Al-Kindy S (2015) Assessment of biventricular function by threedimensional speckle-tracking echocardiography in secondary mitral regurgitation after repair with the MitraClip system. J Am Soc Echocardiogr 28:1070-1082

13. Ledwoch J, Fellner C, Hoppmann P, Thalmann R, Kossmann H, Dommasch M, Dirschinger R, Stundl A, Laugwitz KL, Kupatt C (2020) Impact of transcatheter mitral valve repair using MitraClip on right ventricular remodeling. Int J Cardiovasc Imaging 36:811-819

14. Schueler R, Ozturk C, Wedekind JA, Werner N, Stockigt F, Mellert F, Nickenig G, Hammerstingl C (2015) Persistence of iatrogenic atrial septal defect after interventional mitral valve repair with the MitraClip system: a note of caution. JACC Cardiovasc Interv 8:450-459

15. Hart EA, Zwart K, Teske AJ, Voskuil M, Stella PR, Chamuleau SA, Kraaijeveld AO (2017) Haemodynamic and functional consequences of the iatrogenic atrial septal defect following Mitraclip therapy. Neth Heart J Mon J Neth Soc Cardiol Neth Heart Found 25:137-142

16. Eden M, Leeb L, Frey N, Rosenberg M (2020) Haemodynamics of an iatrogenic atrial septal defect after MitraClip implantation. Eur J Clin Investig 50:e13295

17. Melisurgo G, Ajello S, Pappalardo F, Guidotti A, Agricola E, Kawaguchi M, Latib A, Covello RD, Denti P, Zangrillo A, Alfieri O, Maisano F (2014) Afterload mismatch after MitraClip insertion for functional mitral regurgitation. Am J Cardiol 113:1844-1850

18. Godino C, Salerno A, Cera M, Agricola E, Fragasso G, Rosa I, Oppizzi M, Monello A, Scotti A, Magni V, Montorfano M, Cappelletti A, Margonato A, Colombo A (2016) Impact and evolution of right ventricular dysfunction after successful MitraClip implantation in patients with functional mitral regurgitation. Int $\mathrm{J}$ Cardiol Heart Vasc 11:90-98

19. Kaneko H, Neuss M, Weissenborn J, Butter C (2016) Prognostic significance of right ventricular dysfunction in patients with functional mitral regurgitation undergoing MitraClip. Am J Cardiol 118:1717-1722

20. Soetemann DB, Boenner F, Zeus T, Veulemans V (2018) Secondary right heart failure due to haemodynamically relevant iatrogenic atrial septal defect: does the sequence of structural interventions sometimes matter? A case report. Eur Heart J Case Rep 2:yty119

21. Blazek S, Unterhuber M, Rommel KP, von Roeder M, Kresoja KP, Kister T, Besler C, Fengler K, Sandri M, Daehnert I, Thiele H, Lurz P (2021) Biventricular physiology of iatrogenic atrial septal defects following transcatheter mitral valve edge-to-edge repair. JACC Cardiovasc Interv 14:54-66

22. Lurz P, Unterhuber M, Rommel K-P, Kresoja K-P, Kister T, Besler C, Fengler K, Sandri M, Daehnert I, Thiele H, Roeder MV, Blazek S (2021) Closure of iatrogenic atrial septal defect after transcatheter mitral valve repair. Circulation 143:292-294

23. Taramasso M, Benfari G, van der Bijl P, Alessandrini H, AttingerToller A, Biasco L, Lurz P, Braun D, Brochet E, Connelly KA, de Bruijn S, Denti P, Deuschl F, Estevez-Loureiro R, Fam N, Frerker C, Gavazzoni M, Hausleiter J, Ho E, Juliard JM, Kaple R, Besler C, Kodali S, Kreidel F, Kuck KH, Latib A, Lauten A, Monivas V, Mehr M, Muntane-Carol G, Nazif T, Nickening G, Pedrazzini G, Philippon F, Pozzoli A, Praz F, Puri R, Rodes-Cabau J, Schafer U, Schofer J, Sievert H, Tang GHL, Thiele H, Topilsky Y, Rommel KP, Delgado V, Vahanian A, Von Bardeleben RS, Webb JG, Weber M, Windecker S, Winkel M, Zuber M, Leon MB, Hahn RT, Bax JJ, Enriquez-Sarano M, Maisano F (2019) Transcatheter versus medical treatment of patients with symptomatic severe tricuspid regurgitation. J Am Coll Cardiol 74:2998-3008

24. Sugiura A, Kitahara H, Iwahana T, Suzuki N, Okada S, Miyauchi H, Kobayashi Y, Werner N (2020) Association of heart failure duration with clinical prognosis in advanced heart failure. Clin Res Cardiol 109:350-357 